This document is confidential and is proprietary to the American Chemical Society and its authors. Do not copy or disclose without written permission. If you have received this item in error, notify the sender and delete all copies.

\title{
Bidentate Lewis Acid Catalyzed Domino Diels-Alder Reaction of Phthalazine for the Synthesis of Bridged Oligocyclic Tetrahydronaphthalenes
}

\begin{tabular}{|r|l|}
\hline Journal: & Organic Letters \\
\hline Manuscript ID & ol-2016-002766.R1 \\
\hline Manuscript Type: & Communication \\
\hline Date Submitted by the Author: & $29-$ Feb-2016 \\
\hline Complete List of Authors: & $\begin{array}{l}\text { Schweighauser, Luca; Justus-Liebig Universität, Institut Organische Chemie } \\
\text { Bodoky, Ina; University of Basel, Department of Chemistry } \\
\text { Kessler, Simon; University of Basel, Department of Chemistry } \\
\text { Häussinger, Daniel; Universität Basel, Chemie } \\
\text { Donsbach, Carsten; Philipps-Universität Marburg, Fachbereich Chemie and } \\
\text { Wissenschaftliches Zentrum für Materialwissenschaften (WZMW) } \\
\text { Wegner, Hermann; Justus-Liebig Universität, Institut Organische Chemie }\end{array}$ \\
\hline
\end{tabular}


The ability to construct complex molecules in an economically and environmentally friendly way is highly interesting, especially in view of a shortage in energy and resources. ${ }^{1-3}$ Domino reactions allow streamlining the overall process by combining multiple transformation in one operation. Based on the domino methodology, large libraries can be prepared in a fast and concise manner containing, for instance, small bioactive molecules. ${ }^{4}$ Such low-cost libraries allow a systematic investigation of the chemical space..$^{5-9}$ Diels-Alder reactions represent a highly potent component in this context because they enable the creation of two bonds and up to four stereogenic centers in a single diastereoselective step. It was shown that merging multiple Diels-Alder reactions increases the potential even further. ${ }^{10}$ Diels-Alder reactions can also be combined with Knoevenagel condensations ${ }^{11}$ or other cycloadditions. ${ }^{12}$ Hence, the versatility of the domino concept bears high prospects for medicinal ${ }^{13,14}$ as well as material sciences. ${ }^{15}$ One variant, the inverse electrondemand Diels-Alder reaction (IEDDA), has been established as a very convenient reaction for the synthesis of aromatic compounds. ${ }^{16,17}$ It was also introduced into domino processes with great success as independently reported by Boger $^{18,19}$ and Kobayashi. ${ }^{20}$
During the last several years, we developed bidentate Lewis acids as effective catalysts for the IEDDA reaction of phthalazines to form substituted naphthalenes. ${ }^{21,22}$ We used the easily accessible 5,10-dimethyl-5,10-dihydroboranthrene (1) as a catalyst for these transformations. The idea was later expanded to the preparation of cyclopropane substituted dihydronaphthalenes via a subsequent [3,9]-sigmatropic rearrangement. ${ }^{23}$

Scheme 1. Bidentate Lewis acid catalyzed IEDDA reaction with in-situ generated enamines.

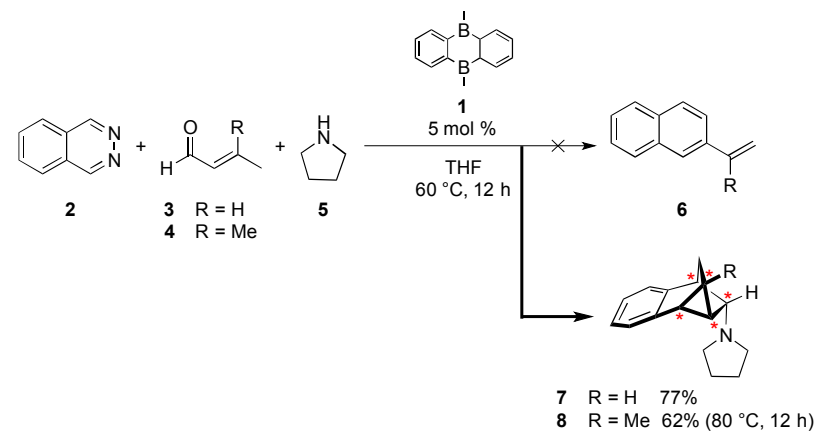


The high capability of the method was demonstrated by the direct application of in-situ generated enamines as dienophiles, ${ }^{24}$ which is a powerful approach in such IEDDA reaction schemes. ${ }^{25-28}$ In this way, dienophiles can be produced directly from aldehydes and amines, widely broadening the scope of the reaction. Recently, the concept of bifunctional bis-boron catalysts was extended to other processes as the reduction of carbon dioxide ${ }^{29}$ or the dehydrogenation of ammonia borane. ${ }^{30}$

When investigating the scope of the bidentate Lewis acid catalyzed IEDDA of phthalazine (2) with in-situ generated enamines to form substituted naphthalenes, the $\alpha, \beta$ unsaturated aldehyde 3 was applied as starting material. Surprisingly, the reaction did not lead to the expected vinyl naphthalene $\mathbf{6}^{24}$ Instead, the tricyclic 1,2,3,4tetrahydronaphthalene 7 was formed in $77 \%$ yield (Scheme 1). The product contained five stereogenic centers and a cyclopropane as key structural elements. It was isolated as a single diastereomer. ${ }^{31}$ Tetrahydronaphthalene 7 is a conformationally restricted derivative of phenylethylamine. Various biologically active compounds e.g. amphetamine, in which conformation plays an important role for activity, are based on this scaffold. ${ }^{32,33}$

Besides crotonaldehyde (3) the methyl-substituted aldehyde 4 led to the corresponding methyl substituted product 8 in $62 \%$ yield. The reaction temperature had to be increased to $80{ }^{\circ} \mathrm{C}$ due to the higher steric hindrance. No major sideproduct was identified. In both experiments the exo isomer was favored and the only isolated product (determined by 2D-NMR spectroscopy). $\mathrm{N}_{2}$-formation was already observed at $\mathrm{rt}$ immediately after combining the starting materials with catalyst $\mathbf{1}$. However, the reactions were heated over night to achieve full conversion.

The dienophile necessary for the second Diels-Alder reaction with normal electron-demand could also be introduced within the amine component (Table 1). With allyl amine 9 tricyclic products built on 5- and 6-membered rings were achievable in a highly selective manner. The reaction could be conducted successfully with a variety of differently substituted aldehydes and led, again, exclusively to the exo products. When using valeraldehyde (10a), full conversion and an isolated yield of $93 \%$ was achieved (Table 1, entry 1). It was also possible to apply the branched isovaleraldehyde (10b), which gave the target compound in $71 \%$ yield (Table 1, entry 2). The reason for the drop in yield can be found in the higher steric demand of the aldehyde component. In experiments with smaller aliphatic aldehydes e.g. propionaldehyde the desired product was also formed. However, yields were lower and the reaction did not proceed as cleanly. In this case, competing aldol reactions might be the cause. Aromatic residues were successfully used, such as the phenyl substituted aldehyde 10c. With this aldehyde component, again, a very high isolated yield of $93 \%$ could be reached (Table 1, entry 3 ). To further increase the complexity of the tricyclic products we selected aldehydes containing a stereogenic center in $\beta$-position (Table 1 , entry $4,5 \& 6$ ). In this way we were able to form tricyclic tetrahydronaphthalenes with six stereogenic centers. The products of these experiments were isolated as a mixture of two diastereomers as the aldehydes were applied as racemic mixtures. The ratio of the two-formed stereoisomers varied between 1.2:1 and 1.7:1 illustrating a small excess of one isomer. As men- tioned above, we observed that the yields slightly decreased upon substitution in $\beta$-position (Table 1 , entries $2,4 \& 5$ ). Gratifyingly, the method allowed also introducing functional groups such as esters (Table 1, entry 5). Although these groups bear the potential to coordinate to the bidentate Lewis acid, the reaction provided cleanly the desired product in $70 \%$ yield. Additionally, furan aldehyde 10f (Table 1, entry 6 ) was tested. The high yield of $87 \%$ illustrates the high selectivity of the reaction, as the furan could also act as a diene in Diels-Alder reactions.

Table 1. Scope of the bidentate Lewis acid catalyzed domino IEDDA-DA-reaction.
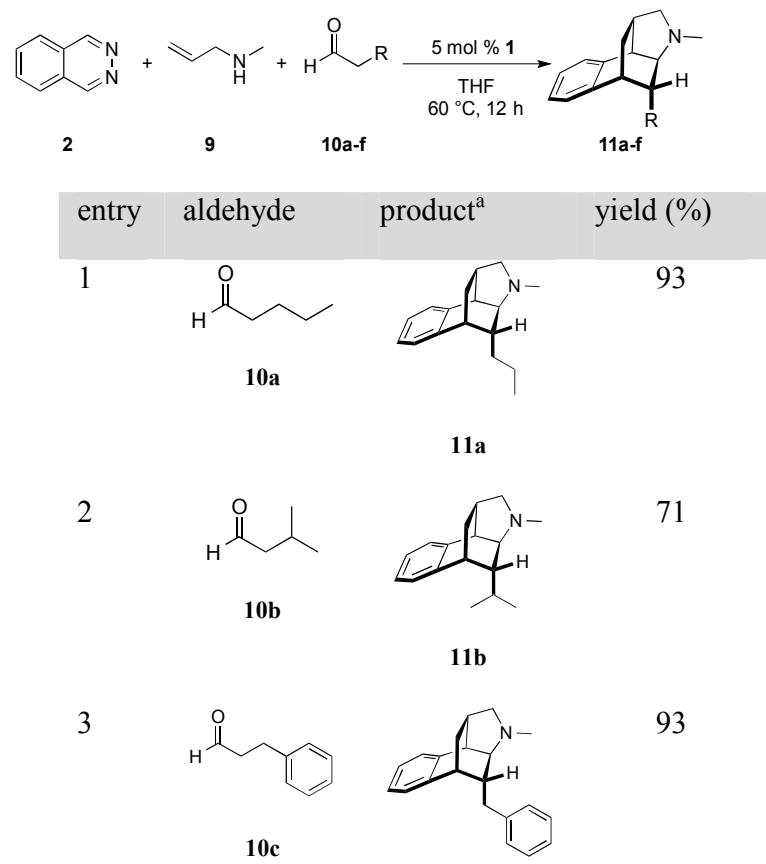

71

93

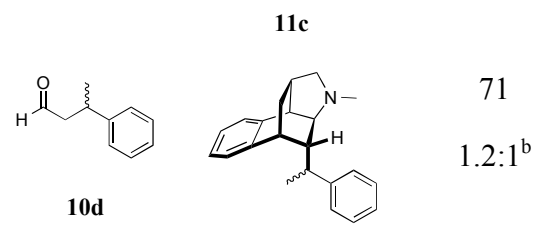

5

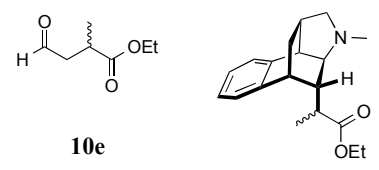

70

$1.6: 1^{b}$

6

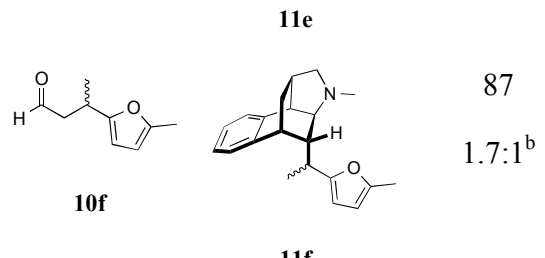

${ }^{\text {a }}$ Isolated as single diastereomers. Only one enantiomer of every product is represented for clarity. ${ }^{b}$ Isolated as a mixture of two diastereomers. The ratio was determined by NMR spectroscopy. 
X-ray analysis of products 8 and 11e was achieved from crystals formed by slow evaporation of $n$-pentane at $-20{ }^{\circ} \mathrm{C}$. The data illustrates the ring strain generated in the domino process (Figure 1). The tricyclic structure of product $\mathbf{8}$ dominated by the cyclopropane motif, contains a cyclohexane pattern with twisted conformation and bond angles up to $119^{\circ}$.
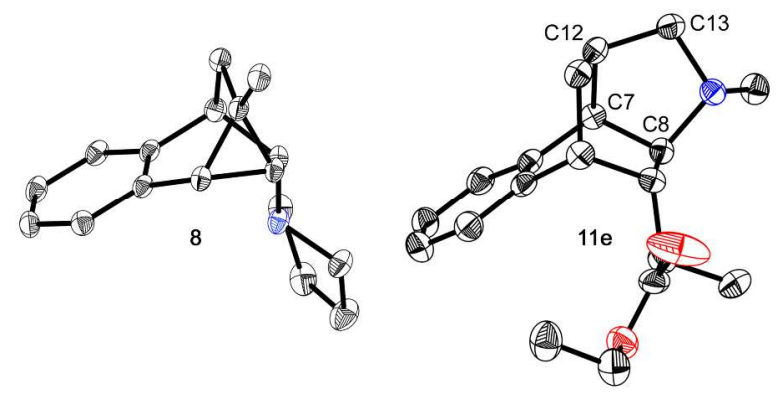

Figure 1. X-ray structures of products 8 and 11e (thermal ellipsoids drawn at $50 \%$ probability, hydrogen atoms and water molecules omitted for clarity)

A mechanism for the domino reaction is proposed in Scheme 2. In a first step the bidentate Lewis acid 1 coordinates to the phthalazine (2). The complexation reduces the electron density of the phthalazine facilitating the IEDDA reaction step with the in-situ generated enamines 13. It is proposed that the more electron-rich enamine acts as dienophile in the first Diels-Alder. This transformation is suggested to proceed with the more stable $E$-isomers of the enamines, which is in agreement to the exo conformation of the isolated products.

Scheme 2. Catalytic cycle of the domino reaction leading to products 11a-f.

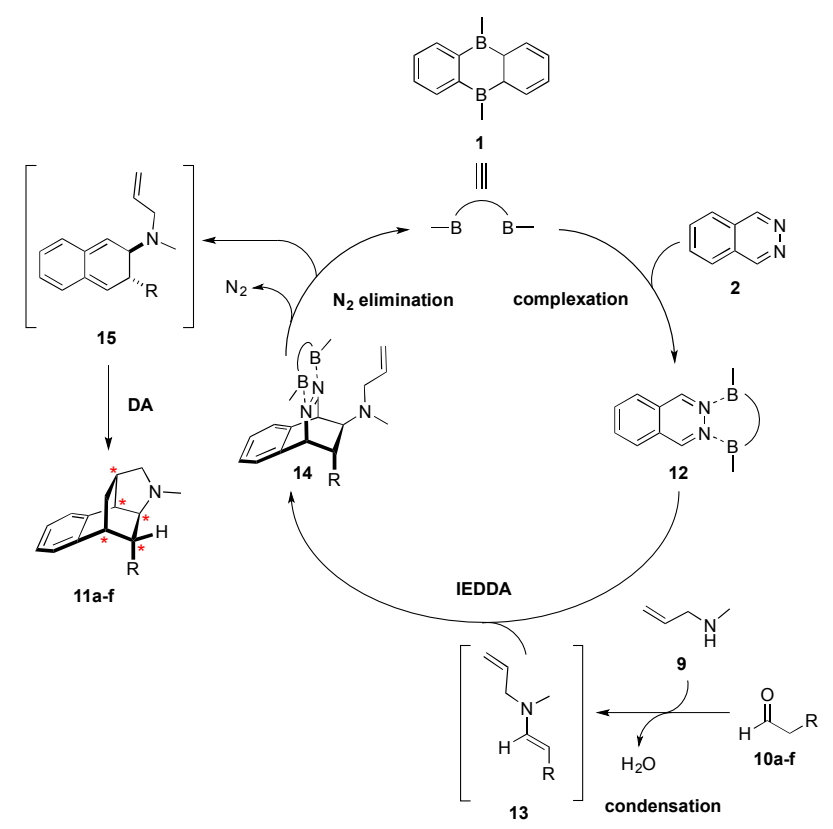

Interestingly, neither the amine nor the water produced in the enamine formation did influence the activity of the cata- lyst. Elimination of $\mathrm{N}_{2}$ forms the highly reactive $o$ quinodimethane intermediate $\mathbf{1 5}$ and releases the catalyst. Such $o$-quinodimethane intermediates have biradical charac$\operatorname{ter}^{34,35}$ and are described as very powerful dienes for DielsAlder reactions. ${ }^{36,37}$ Consequently, an intramolecular DielsAlder reaction terminates the sequence as the last step. Noteworthy, both bond forming events, in the inverse as well as in the normal electron-demand Diels-Alder occur at the same two carbon atoms.

The concept was further expanded by choosing 1,4cyclohexanedione (16) as a bifunctional carbonyl component (Scheme 3). The reaction mixture was stirred at $80^{\circ} \mathrm{C}$ for five days to isolate the complex tetracyclic diamine $\mathbf{1 7}$ in $53 \%$ yield ( $89 \%$ based on amine). The longer reaction rate was required due to the smaller amount of enamine in the reaction mixture and the higher steric demand (ketone vs. aldehyde). Dione 16 can form two enamine functionalities, which can act both as an electron rich dienophile. Consequently, the bis-enamine of $\mathbf{1 6}$ undergoes a bidentate Lewis acid catalyzed IEDDA reaction with the first enamine, which is then followed by $\mathrm{N}_{2}$ extrusion leading to the $o$ quinodimethane intermediate $\mathbf{1 8}$. Intermediate 18 undergoes the domino DA step with the second enamine leading to product $\mathbf{1 7}$, which contains six stereogenic centers and was formed again as a single diastereomer.

Scheme 3. Formation of tetracyclic product 17 in the diastereoselective bidentate Lewis acid catalyzed Domino reaction.

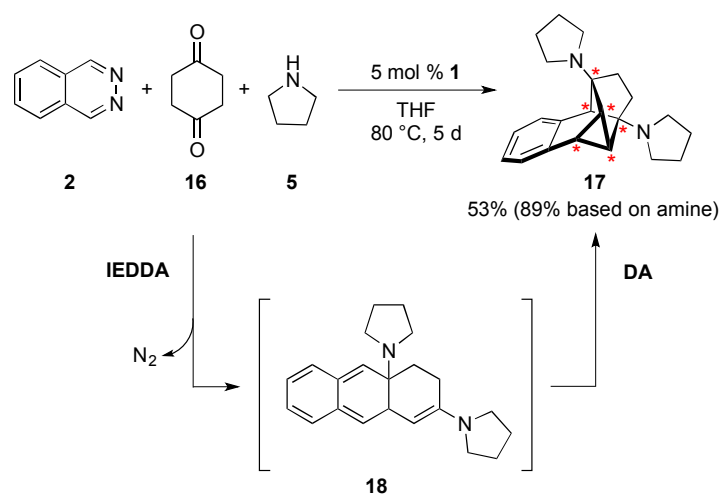

In conclusion, we developed a bidentate Lewis acid catalyzed domino IEDDA-DA process that allows the synthesis of bridged tri- and tetracyclic tetrahydronaphthalenes with up to six stereogenic centers in a single step. Commercially available amines, aldehydes/ketones and phthalazine were used as starting materials. The initial catalyzed IEDDA reaction leads to a highly reactive $o$-quinodimethane intermediate, which enables the second intramolecular cycloaddition. The formed tetrahydronaphthalenes were isolated as single diastereomers. Only in the presence of racemic starting material with an additional stereogenic center two diastereomers were obtained, as expected. The products are complex derivatives of phenylethylamine and demonstrate that this new domino process is a suitable method to quickly build up chemical libraries containing molecules with high structural diversity. Future work will address expanding the scope of the reaction and investigating the biological activity of the products. 


\section{ASSOCIATED CONTENT}

\section{Supporting Information}

The Supporting Information is available free of charge on the ACS Publications website.

Experimental details, analytical data and NMR spectra are provided (PDF), as well as X-ray crystal structure data for $\mathbf{8}$ and 11e (CIF). In addition, the X-ray structures were deposited on the Cambridge Structural Database (CCDC 1449732 and 1449733).

\section{AUTHOR INFORMATION}

\section{Corresponding Author}

*E-Mail: hermann.a.wegner@org.chemie.uni-giessen.de

\section{Present Addresses}

$\S$ Present address: Arrhenius Laboratory, Organic Chemistry, Stockholm University, 10691 Stockholm, Sweden

\section{Notes}

The authors declare no competing financial interest.

\section{ACKNOWLEDGMENT}

We thank Verena Grundler ${ }^{\dagger}$ for preparative HPLC and Erwin Röcker for mass spectrometry analysis.

\section{REFERENCES}

(1) Tietze, L. F.; Beifuss, U. Angew. Chem. Int. Ed. Engl. 1993, 32, 131-163.

(2) Tietze, L. F. Chem. Rev. 1996, 96, 115-136.

(3) Tietze, L. F.; Brasche, G.; Gericke, K. M. Domino Reactions in Organic Synthesis; Wiley-VCH Verlag GmbH \& Co. KGaA, 2006.

(4) Tietze, L. F.; Lieb, M. E. Curr. Opin. Chem. Biol. 1998, 2, 363-371.

(5) Lipinski, C.; Hopkins, A. Nature 2004, 432, 855-861.

(6) Dobson, C. M. Nature 2004, 432, 824-828.

(7) Koch, M. A.; Schuffenhauer, A.; Scheck, M.; Wetzel, S.; Casaulta, M.; Odermatt, A.; Ertl, P.; Waldmann, H. Proc. Natl. Acad. Sci. U. S. A. 2005, 102, 17272-17277.

(8) Wilson, R. M.; Danishefsky, S. J. Angew. Chem. Int. Ed. 2010, 49, 6032-6056.

(9) Wetzel, S.; Bon, R. S.; Kumar, K.; Waldmann, H. Angew. Chem. Int. Ed. 2011, 50, 10800-10826.

(10) For an example in natural product synthesis, see: Turner, C. I.; Williamson, R. M.; Turner, P.; Sherburn, M. S. Chem. Commun. 2003, 1610-1611.

(11) Tietze, L. F.; Evers, H.; Töpken, E. Angew. Chem. Int. Ed. 2001, 40, 903-905.
(12) Campbell, E. L.; Skepper, C. K.; Sankar, K.; Duncan, K. K.; Boger, D. L. Org. Lett. 2013, 15, 5306-5309.

(13) Vanderwal, C. D.; Vosburg, D. A.; Weiler, S.; Sorensen, E. J. J. Am. Chem. Soc. 2003, 125, 5393-5407.

(14) Evans, D. A.; Starr, J. T. J. Am. Chem. Soc. 2003, 125, 13531-13540.

(15) Criado, A.; Peña, D.; Cobas, A.; Guitián, E. Chem. - Eur. J 2010, 16, 9736-9740.

(16) Marcelis, A. T. M.; Van Der Plas, H. C. Tetrahedron 1989 45, 2693-2702.

(17) Anderson, E. D.; Boger, D. L. J. Am. Chem. Soc. 2011, 133, 12285-12292.

(18) Kato, D.; Sasaki, Y.; Boger, D. L. J. Am. Chem. Soc. 2010, 132, 3685-3687.

(19) Sasaki, Y.; Kato, D.; Boger, D. L. J. Am. Chem. Soc. 2010, 132, 13533-13544

(20) Suzuki, T.; Miyajima, Y.; Suzuki, K.; Iwakiri, K.; Koshimizu, M.; Hirai, G.; Sodeoka, M.; Kobayashi, S. Org. Lett 2013, 15, 1748-1751.

(21) Kessler, S. N.; Wegner, H. A. Org. Lett. 2010, 12, 40624065.

(22) Kessler, S. N.; Neuburger, M.; Wegner, H. A. Eur. J. Org. Chem. 2011, 2011, 3238-3245.

(23) Kessler, S. N.; Neuburger, M.; Wegner, H. A. J. Am. Chem Soc. 2012, 134, 17885-17888.

(24) Schweighauser, L.; Bodoky, I.; Kessler, S.; Häussinger, D.; Wegner, H. Synthesis 2012, 44, 2195-2199.

(25) Boger, D. L.; Panek, J. S. J. Org. Chem. 1981, 46, 2179 2182.

(26) Boger, D. L.; Panek, J. S.; Meier, M. M. J. Org. Chem. 1982, 47, 895-897.

(27) Okatani, T.; Koyama, J.; Tagahara, K.; Suzuta, Y. Heterocy cles 1987, 26, 595.

(28) Lorion, M.; Guillaumet, G.; Brière, J.-F.; Suzenet, F. Org. Lett. 2015, 17, 3154-3157.

(29) Lu, Z.; Hausmann, H.; Becker, S.; Wegner, H. A. J. Am. Chem. Soc. 2015, 137, 5332-5335.

(30) Lu, Z.; Schweighauser, L.; Hausmann, H.; Wegner, H. A. Angew. Chem. Int. Ed. 2015, 54, 15556-15559.

(31) A similar tricyclic structure was described as a product in a photochemical process starting from benzo[6,7]bicyclo[3.2.1]octa-2,6-diene: Hahn, R. C.; Rothman, L. J. J. Am. Chem. Soc. 1969, 91, 2409-2410.

(32) Grunewald, G. L.; Ye, Q.; Sall, D. J.; Criscione, K. R.; Wise, B. Mol. Pharmacol. 1989, 35, 93-97.

(33) Grunewald, G. L.; Ruth, J. A.; Kroboth, T. R.; Kamdar, B. V.; Patil, P. N.; Salman, K. N. J. Pharm. Sci. 1976, 65, 920 923.

(34) Gisin, M.; Wirz, J. Helv. Chim. Acta 1976, 59, 2273-2277.

(35) Miyoshi, H.; Nobusue, S.; Shimizu, A.; Hisaki, I.; Miyata, M.; Tobe, Y. Chem. Sci. 2013, 5, 163-168.

(36) Segura, J. L.; Martín, N. Chem. Rev. 1999, 99, 3199-3246.

(37) Dell'Amico, L.; Vega-Peñaloza, A.; Cuadros, S.; Melchiorre, P. Angew. Chem. Int. Ed. 2016, 55, 3313-3317. 